\title{
Phytotoxicity Evolution of Biowastes Undergoing Aerobic Decomposition
}

\author{
M. R. Soares, ${ }^{1,2}$ C. Matsinhe, ${ }^{2}$ S. Belo, ${ }^{2}$ M. J. Quina, ${ }^{2}$ and R. Quinta-Ferreira ${ }^{2}$ \\ ${ }^{1}$ Cernas-Natural Resources, Environment and Society Research Centre, Coimbra College of Agriculture, \\ Polytechnic Institute of Coimbra, Bencanta, 3040-316 Coimbra, Portugal \\ ${ }^{2}$ Department of Chemical Engineering, CIEPQPF-Research Centre on Chemical Processes Engineering and Forest Products, \\ University of Coimbra, Rua Sílvio Lima-Pólo II, 3030-290 Coimbra, Portugal \\ Correspondence should be addressed to M. R. Soares; msoares@esac.pt
}

Received 31 January 2013; Revised 27 March 2013; Accepted 8 April 2013

Academic Editor: Yu Liu

Copyright ( $\odot 2013$ M. R. Soares et al. This is an open access article distributed under the Creative Commons Attribution License, which permits unrestricted use, distribution, and reproduction in any medium, provided the original work is properly cited.

This study is mainly focused on the phytotoxicity improvement within five to six weeks of thermophilic composting of biowastes. Two sets of experiments were conducted involving both sawdust and rice husk as bulking agents, which were composted in selfheating reactors with potato-peel industrial waste and grass clippings as organic materials. The main variables observed over time were temperature, oxygen uptake rate (OUR), biodegradability, and germination index (GI). The effects of compost water extracts on seed germination and primary root growth of garden cress (Lepidium sativum) were measured to calculate the germination index (GI). The biodegradability was well assessed by measuring lignin content, using the Klason method. The experimental results showed that initial compositions strongly determined the profiles of phytotoxicity and the period of maturation. The phytotoxicity assessment in the experiments with sawdust revealed that after 39 days of composting, the GI attained the maximum value of $30 \%$, but using rice husk, it was possible to reach $70 \%$ in the same period of time. Our findings showed that, at a certain point, higher cumulative OUR led to lower germination index, and proportional relationship between the cumulative OUR and GI was observed, after thermophilic phase.

\section{Introduction}

Nowadays, the natural resources are consumed at unsustainable rates, and consequently a huge amount of waste is produced, which can cause environmental damage if it is not well managed. In particular, the European Union policy states that the diversion of biowastes from landfill to anaerobic digestion or to composting should be improved for reducing pollution and recovering energy or soil conditioner materials.

Composting can be defined as the aerobic microbial decomposition of organic matter, under controlled conditions that allow the development of thermophilic temperatures as a result of the heat released in the biochemical reactions, leading to a stabilized and sanitized final product (free of pathogens and seeds), commonly known as compost [1]. Indeed, although composting is not a recent technology, it can be considered as one of the most flexible methods for handling biodegradable wastes, from small scales such as household bins to large industrial plants [2]. To successfully accomplish composting, favorable physical and chemical conditions to the growth and activity of microorganisms should be promoted, accounting for some essential nutrients, namely, carbon and nitrogen as well as oxygen for metabolic activity.

In this context, it is important to ensure that the starting composting mixture is sufficiently biodegradable to promote aerobic breakdown of organic matter with consequent development of thermophilic temperatures [3-5]. As a result, the prediction and determination of the biodegradable fraction of a starting composting mixture is of major importance [610], and this issue will be addressed in our study. Several biological testing methods are available for the characterization and appraisal of organic matter biodegradability which are mainly based on the biological respiration potential assessment of the materials in aerobic conditions [11, 12]. It is well established that lignin is the main precursor for 
humic substances that is, mainly humified and not mineralized during degradation in a compost environment [13]. Consequently, materials with high contents of lignin are in general poorly biodegradable [14]. In fact, the knowledge of the material lignin content may provide a nonbiological test method for evaluating biodegradability [1]

The finished compost can be applied as soil improver, mulch, or as a medium to grow plants. However, it is very important to reinforce end users' confidence in order to create a marketable product. For that, the stability and the quality of the finished compost should be well established. Indeed, it is necessary to understand the characteristics of the end product in order to avoid any undesirable effect [15]. In this respect, maturity is one of the most significant properties of compost quality, which involves the degree of decomposition of phytotoxic organic substances produced during the active composting stage and as well as the absence of pathogens and viable weed seeds [16]. In practical terms, this concept refers to the agricultural "value" of the compost regarding its effects on the soil and plants response [17]. The phytotoxicity can be evaluated during the composting for assessing the maturation, and so far various methods have been proposed, most of them based on seed germination bioassays [18]. In our study, the germination index (GI) was determined in aqueous extracts by using garden cress (Lepidium sativum), since this is a well-known method allowing fast results and high sensitivity to toxins as well. This bioassay estimates if a material contains substances that inhibit the seed germination and root growth. Some experimental results have been shown that the negative effects on plants may occur due to some substances that induce high microbial activity that can block the existing soil-available nitrogen or introduce phytotoxic substances in soil, such as heavy metals, phenolic compounds, ethylene and ammonia, and excess accumulation of salts or organic acids [18].

Some studies have reported the linear dependence between germination tests (maturity parameter) and aerobic biological activity of the compost measured by static respirometric methods, expressed in terms of oxygen consumption (stability indicator) [19-21].

In fact, in theory one may expect these two parameters to be negatively correlated, which means that as the biological activity increases, the germination indexes decreases indicating a higher phytotoxicity potential [21]. However, Gea et al. [22] pointed out that biological activity quantified by static respirometric tests was significantly lower than the one assessed by online measurement of oxygen uptake rate (OUR) during composting evolution, especially during the early stages of composting.

Therefore, the main novelty of the present work is to evaluate the phytotoxicity improvement during the composting of biowastes and to appraise the existence of linear dependence between the germination index and on-line measured biological activity during process evolution, expressed as cumulative OUR.

In addition, the biodegradability levels of the starting mixtures and along the process were investigated as well. The mixtures tested were obtained by combining potato peel industrial waste (PP), grass clippings (GCs), sawdust (SD), and rice husk $(\mathrm{RH})$ in different proportions.

\section{Materials and Methods}

2.1. Experimental Apparatus. Experiments were performed in a system of self-heating reactors arranged in parallel, each with $120 \mathrm{~L}$ of internal volume $(0.7 \mathrm{~m}$ high and $0.44 \mathrm{~m}$ in diameter) and isolated with a rubber-based elastomeric material (Aeroflex MSR). The compressed air flow enters at the bottom of the reactors, and is uniformly distributed across a perforated Perspex plate. On the top of the reactors there are two openings for the introduction of the temperature sensor and for releasing the gases generated in biological reactions as well as the feed air not consumed. The reactors were equipped with a data acquisition system for on-line monitoring of temperature and oxygen concentration, and the feed air flow rate was measured with rotameters. In general, the air flow rate was controlled in order to maintain the oxygen concentration of the outlet gas in the range of $5 \%$ to $15 \%(\mathrm{v} / \mathrm{v})$ and to control the temperature of the composting material in the reactor as well.

\subsection{Starting Materials and Composting Mixture Compositions.} Potato peel (PP) was gathered at a Portuguese industry of potato chips, sawdust (SD) provided by a local pine sawmill, rice husk $(\mathrm{RH})$ collected in a rice husking factory, and grass clippings (GCs) obtained from a garden maintenance service of a national football stadium. These materials were used in composting experiments immediately after their collection. Grass clippings were sieved through a $5 \mathrm{~cm}$ mesh, in order to obtain a homogenous material in size and shape, and the other materials did not require any specific treatment. The initial composition of each mixture tested is shown in Table 1.

The composting experiments inside the self-heating reactors lasted about 20 days for SD and 25 days for experiments involving RH. The biowastes were periodically mixed on a daily basis to achieve homogeneous conditions. Once a week, samples were taken for further analysis.

After composting in self-heating reactors, mixtures were allowed to conclude maturation phase in small piles that were homogenized and moisture corrected every week, until 39 days of composting.

2.3. Analytical Methods. The moisture content was determined as the loss in weight in an oven at $105^{\circ} \mathrm{C}$ to constant weight. The organic matter content was considered equal to the weight loss on dry incineration (VS) of $2.5 \mathrm{~g}$ (dry weight) of sample. Incineration was conducted in a muffle furnace at $550^{\circ} \mathrm{C}$ for at least $4 \mathrm{~h}$, until differences between two successive weighing were less than $0.01 \mathrm{~g}$.

Lignin content was determined by the Klason method, which involves gravimetric measurements using solid samples, air-dried and ground to $<0.22 \mathrm{~mm}$, extracted with sulphuric acid solutions to dissolve the other components [11]. 
Phytotoxicity was assessed by evaluating the effects on seed germination and root growth of aqueous extracts prepared from $10 \mathrm{~g}$ of solid (dry basis) with $100 \mathrm{~mL}$ of distilled water $(L / S=10)$, shaking for $1 \mathrm{~h}$ at room temperature. This suspension was centrifuged for $20 \mathrm{~min}$ to facilitate solid liquid separation, the supernatant was filtered, and $5 \mathrm{~mL}$ of extract obtained were placed in a petri dish containing 10 seeds of Lepidium sativum L. Five replicates per sample were incubated at $25^{\circ} \mathrm{C}$ in dark conditions for $48 \mathrm{~h}$. After this period, the number of germinated seeds and their root length were measured. Besides, a control test was prepared with deionized water. The relative seed germination (RSG), relative root elongation (RRE), and germination index (GI) were calculated by (1)-(3), respectively, as follows:

$$
\begin{aligned}
& \text { RSG (\%) } \\
& =\frac{\text { number of seeds germinated in aqueous extract }}{\text { number of seeds germinated in control }} \times 100
\end{aligned}
$$

$$
\mathrm{RRG}(\%)=\frac{\text { mean root length in aqueous extract }}{\text { mean root length in control }} \times 100 \text {; }
$$

$$
\mathrm{GI}(\%)=\frac{\mathrm{RSG}(\%) \times \operatorname{RRE}(\%)}{100} .
$$

2.4. Biodegradability Assessment. The conversion of organic matter obtained experimentally, $X_{\mathrm{VS}}$, can be calculated according to the following:

$$
X_{\mathrm{VS}}=\frac{\mathrm{VS}}{\mathrm{VS}_{0}},
$$

where VS and $\mathrm{VS}_{0}$ are the mass of volatile solids at time $t$ and time zero, respectively. Moreover, from the measurement of lignin content of the initial composting mixtures and for each instant $t$, the conversion of organic matter was estimated by

$$
X_{\text {lignin }}=\frac{\mathrm{VS}-\mathrm{VS} \times L / 100}{\mathrm{VS}_{0}-\mathrm{VS}_{0} \times L_{0} / 100},
$$

where $L$ and $L_{0}$ represent the content of lignin and humiclike substances, as percentage of VS, at instant $t$ and at the beginning of the process, respectively.

The maximum conversion of organic matter, $X_{\max }$, can be calculated by (6) considering that all biodegradable organic matter was effectively degraded. Consider

$$
X_{\max }=\frac{100-L}{100} .
$$

In this study, other empirical correlations to predict mixture biodegradability from lignin content were also evaluated. Haug [1] concluded that this parameter is determinant for substrate biodegradability in anaerobic conditions according to the following:

$$
X_{\text {Chandler }}=0.85-0.028 \times L_{0} .
$$

However, in line with results of Komilis and Ham [14], the lignin level was considered less inhibitory to substrate decomposition in aerobic conditions, and a correlation between VS degradation in aerobic conditions and the initial lignin content of the composting mixture was proposed as follows:

$$
X_{\text {Komilis }}=0.85-0.01 \times L_{0} .
$$

2.5. Statistical Analysis. One-way analysis of variance (ANOVA) was used to test the equality of three or more means at one time based on variances. As null hypotheses, it was assumed that the mean values of all populations are equal, and the alternative hypothesis is that at least one mean is different. The level of significance considered was $P=0.05$.

\section{Results and Discussion}

3.1. Phytotoxicity Assessment of Biowastes. The phytotoxicity test allows us to determine whether a material contains any detrimental substances to seed germination or to plant growth. Table 2 shows some physicochemical properties of the tested materials (moisture content, $\mathrm{pH}$, electrical conductivity, and $\mathrm{C} / \mathrm{N}$ ratio), as well as phytotoxicity classification. From the germination index (GI), it can be concluded that the organic biowaste GC is free of phytotoxins that inhibit the germination of Lepidium sativum, since GI attained values above $80 \%[23,24]$. On the contrary, PP is phytotoxic and the bulking agent SD revealed high phytotoxicity, perhaps because of the acidic characteristic of these materials that can affect seed germination development.

In fact, this property is also reflected on seed growth inhibition of the composting mixtures (SD1 to SD3) used in this study, once all of them are classified as very phytotoxic (results shown in the next section). Rice husk was also used as bulking agent, and when tested by itself, it led to the classification of moderately phytotoxic.

\subsection{Composting Trials}

3.2.1. Monitoring of Composting Variables. As biological degradation proceeds, several changes take place at physical, chemical, and biological levels in the mixture, and thus the monitoring of certain variables is required to assess the evolution of the composting process. The temperature is usually regarded as a key parameter of composting, once it reveals whether the mixture is heating up due to exothermic oxidation reactions promoted by microorganisms. The temperature profiles observed during the composting processes in the exact centre of mixtures are illustrated in Figure 1, for reactors SD1 to SD3 and RH1 to RH3.

In both sets of experiments, these results presented the expected behaviour over time for thermophilic composting, where the three classic phases can be well observed [25]. Indeed, for all tests, a short initial stage is visible due to the activity and growth of mesophilic organisms that increase the temperature within the first $24 \mathrm{~h}$ of composting up to $40^{\circ} \mathrm{C}$. Then, a thermophilic phase (over $40^{\circ} \mathrm{C}$ ) was developed and lasted about 7 to 10 days, which promotes biological 
TABLE 1: Initial composition and properties of starting mixtures.

\begin{tabular}{|c|c|c|c|c|c|c|}
\hline \multirow{2}{*}{ Mixtures } & \multicolumn{4}{|c|}{ Composition (\%w/w) } & \multicolumn{2}{|c|}{ Mixture properties } \\
\hline & PP & GC & SD & $\mathrm{RH}$ & VS $(\% w / w)$ & Lignin content (\% VS) \\
\hline SD1 & 53.0 & 39.8 & 7.2 & 0 & 90.8 & 23.9 \\
\hline SD2 & 66.0 & 28.0 & 6.0 & 0 & 92.3 & 21.3 \\
\hline SD3 & 38.7 & 53.0 & 8.3 & 0 & 91.0 & 25.5 \\
\hline RH1 & 58.7 & 19.4 & 0 & 21.9 & 86.7 & nd \\
\hline RH2 & 50.6 & 32.4 & 0 & 17.0 & 85.9 & nd \\
\hline RH3 & 66.0 & 8.1 & 0 & 25.9 & 86.2 & nd \\
\hline
\end{tabular}

nd: not determined.

TABLE 2: Physicochemical properties and phytotoxicity of materials potentially usable in composting.

\begin{tabular}{|c|c|c|c|c|c|c|}
\hline \multirow{2}{*}{ Materials } & \multicolumn{4}{|c|}{ Physicochemical properties } & \multirow{2}{*}{$\begin{array}{c}\text { Phytotoxicity parameters } \\
\text { GI }_{\text {mean }} \pm \text { std error }\end{array}$} & \multirow{2}{*}{ Classification } \\
\hline & $\mathrm{H}(\%)$ & $\mathrm{pH}$ & $\mathrm{EC}(\mathrm{mS} / \mathrm{cm})$ & $\mathrm{C} / \mathrm{N}$ & & \\
\hline \multicolumn{7}{|c|}{ Organic wastes } \\
\hline $\mathrm{PP}$ & 78.68 & 5.39 & 0.84 & 25.5 & $49.6 \pm 6.9$ & Phytotoxic \\
\hline GC & 70.09 & 8.19 & 0.46 & 11.3 & $103 \pm 11.2$ & Nonphytotoxic \\
\hline \multicolumn{7}{|c|}{ Bulking agents } \\
\hline $\mathrm{SD}$ & 12.25 & 5.50 & 0.23 & 68.0 & $0.9 \pm 0.1$ & Very phytotoxic \\
\hline $\mathrm{RH}$ & 10.61 & 6.75 & 0.87 & 57.5 & $74.4 \pm 9.5$ & Moderately phytotoxic \\
\hline
\end{tabular}

degradation of organic materials, while nonthermotolerant organisms were inhibited. Finally, as biodegradable organic matter becomes exhausted, the temperature profile gradually declines and mesophilic activity once again returns for the final maturation phase, during which slower degradation reactions persist involving lignin and other resistant compounds. The mixtures stayed inside self-heating reactors nearly 20 to 25 days, and then they were in the maturation phase outside in small heaps. For reactors with sawdust (SD1 to SD3) the highest temperatures were above $70^{\circ} \mathrm{C}$, and for experiments with rice husk (RH1 to $\mathrm{RH} 3$ ), the maximum temperatures were close to $60^{\circ} \mathrm{C}$ and then lethal to many harmful pathogens. It is important to note that whenever necessary, the air flow through the reactor can be used as a variable to control the maximum temperature.

For oxidizing organic materials during composting, it is required to maintain a certain oxygen concentration (about $12 \%-20 \%)$ in the interparticle spaces. As biological reactions progress, the oxygen concentration for respiration often decreases, and thus this variable should also be monitored. In the present study, the oxygen uptake rate (OUR) profiles were monitored and presented in Figure 2. OUR is expressed in terms of organic matter (VS) content in each instant that was calculated by assuming their removal proportional to oxygen consumption between mixture sampling events.

Organic wastes have been classified by Barrena and coworkers [9] in three main categories based on the rate of oxygen consumption due to biological activity: (i) high biodegradable (respiration activity higher than $5 \mathrm{mg} \mathrm{O}_{2} \cdot \mathrm{gVS}^{-1} \mathrm{~h}^{-1}$ ); (ii) moderate biodegradable (respiration activity within 2 to $5 \mathrm{mg} \mathrm{O}_{2} \cdot \mathrm{gVS}^{-1} \mathrm{~h}^{-1}$ ); (iii) low biodegradable (respiration activity lower than $2 \mathrm{mg} \mathrm{O}_{2} \cdot \mathrm{gVS}^{-1} \mathrm{~h}^{-1}$ ). In our work, the mixtures reached the level of moderate to high biodegradability, but higher OUR values were attained in SD mixtures with higher potato peel content (SD1 and SD2).

It is also well established that composting mixtures with an OUR lower than $500 \mathrm{mg} \mathrm{O}_{2} \mathrm{~kg} \mathrm{OM}^{-1} \mathrm{~h}^{-1}$ [26] can be considered stable, meaning that a high rate of decomposition of organic matter during composting was achieved, and correspondently biological activity is low. For the cases analysed, approximately 14 to 15 days were necessary to reach stability.

Besides the temperature and OUR variables, also the biodegradability was assessed over time for reactors SD1 to SD3. This is an important property in composting and can be defined as the extent to which organic matter is degraded, (4), representing then the fraction of VS (organic matter) that is prone to decompose during biological oxidation.

Figures 3(a)-3(c) show a good agreement between the conversion of organic matter profiles obtained experimentally, $X_{\mathrm{VS}}$ by (4), and the ones estimated from the quantification of lignin over time, $X_{\text {lignin }}$ by (5). The horizontal lines included in these figures correspond to the maximum conversion of organic matter predicted by using $(6)\left(X_{\max }\right)$ and (8) $\left(X_{\text {max_Komilis }}\right)$.

The correlation often referred in the literature to appraisal the potential of biodegradation, $X_{\text {Chandler }}$, and indicated in (7) was developed for anaerobic process. Its aplication to our experimental data failled, because the estimated values were too small, or even negative due to the high lignin content of the tested mixtures (more than $30 \% \mathrm{VS}$ ). For reactors SD1 to SD3, $X_{\text {Komilis }}$ calculated according to (8) adequately predicted the biodegradability of organic matter. On the other hand, the maximum conversion of organic matter quantified by (6) overestimated our experimental data. 


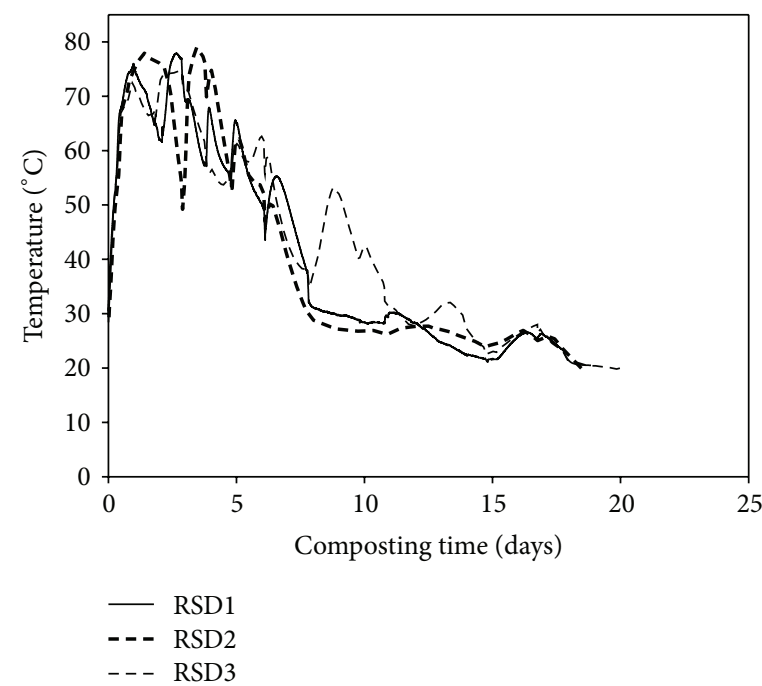

(a)

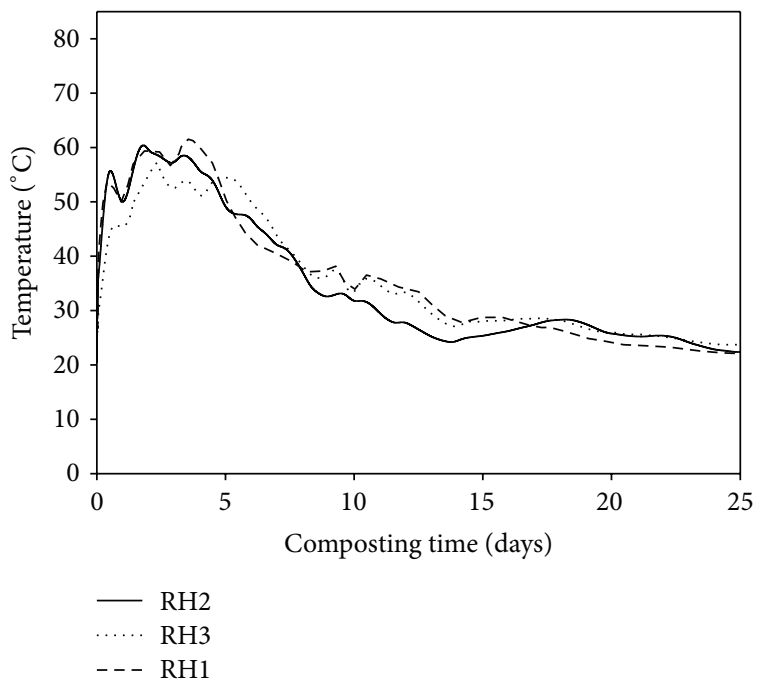

(b)

FIgURE 1: Temperature profiles in reactors (a) SD1 to SD3 and (b) RH1 to RH3.

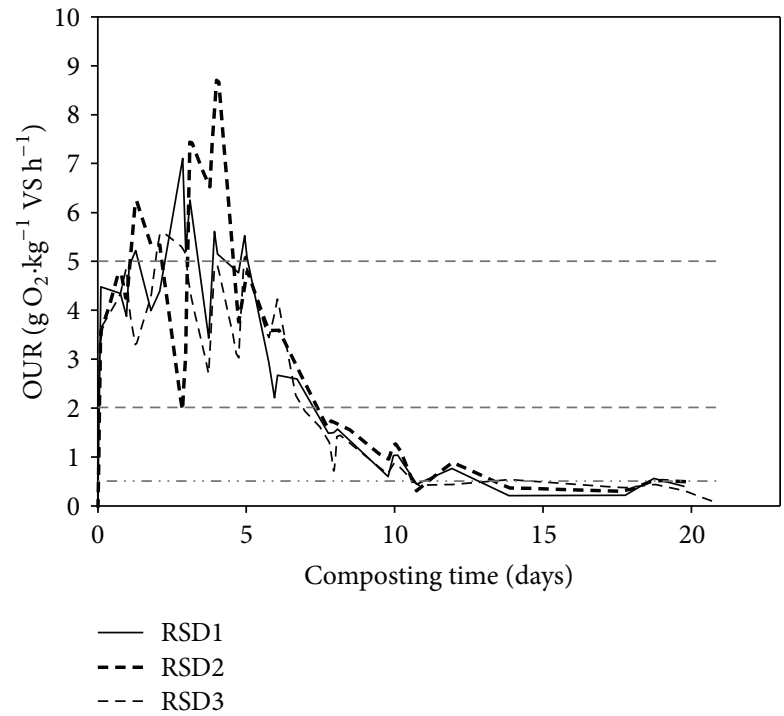

(a)

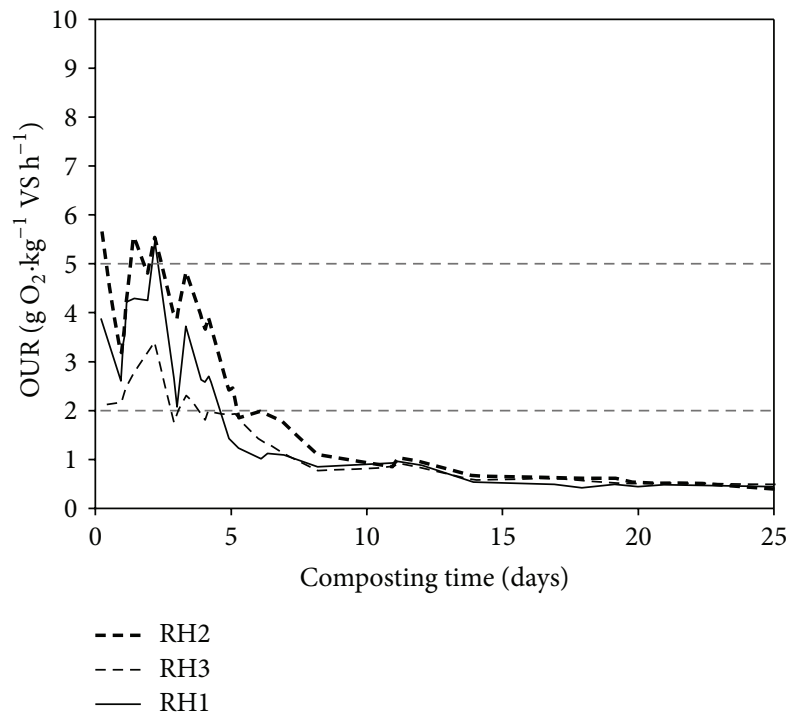

(b)

FIGURE 2: Temporal profile of oxygen uptake rate for reactors (a) SD1 to SD3 and (b) RH1 to RH3.

3.2.2. Phytotoxicity Evolution Over Time. During the composting processes, complex biochemical reactions take place, leading to not only the breakdown of certain organic compounds and the formation of simpler molecules and ions (e.g., $\mathrm{NH}_{4}{ }^{+}$), but also to some degree of polymerization being humic-like substances synthesized. Besides, the formation or disappearance of substances is dependent on various factors such as community of microorganisms, temperature, aeration degree, moisture, and free air space. Therefore, it is not simple to predict the compost quality evolution over time. In particular, the phytotoxic characteristics can vary according to different and unpredictable patterns. As aforementioned, our study focuses on the phytotoxicity progress by measuring germination index through Lepidium sativum seeds. The evolution of GI during composting process is presented in Figures 4(a)-4(b).

The evolution of GI for mixtures with sawdust (SD), Figure 4(a), revealed that germination of seeds in the initial mixtures was practically absent. This was somewhat expected, given that SD and PP also revealed very low GI (Table 2). The GI values of SD1 to SD3 solid matrices remained very low until the 18th day. The reason of these low values can be attributed to the formation of phytotoxic substances during the active phase of composting that impair seed germination, such as ammonium ions, fatty acids, and low molecular weight phenolic acids $[27,28]$. On the other hand, high values 


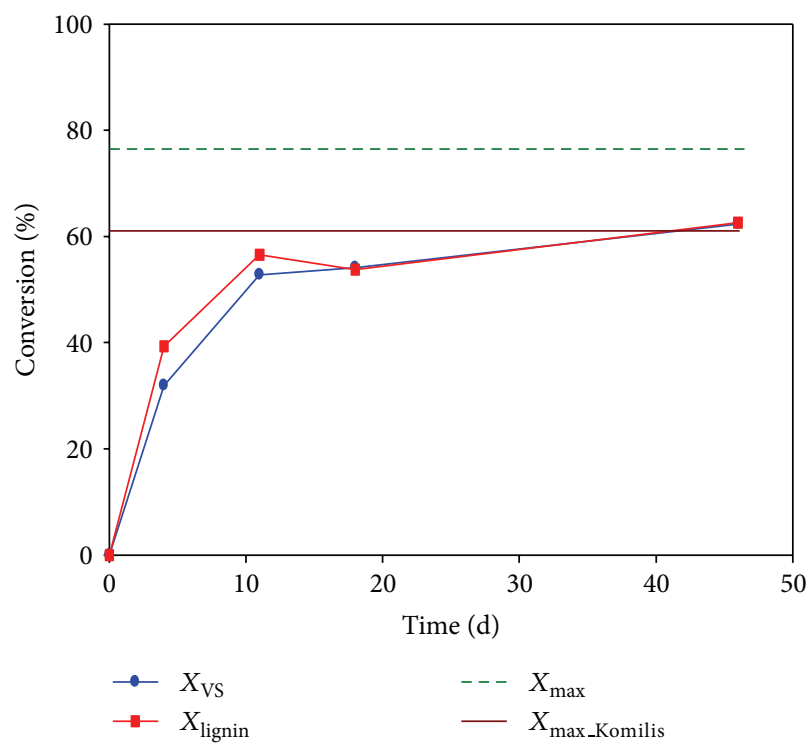

(a)

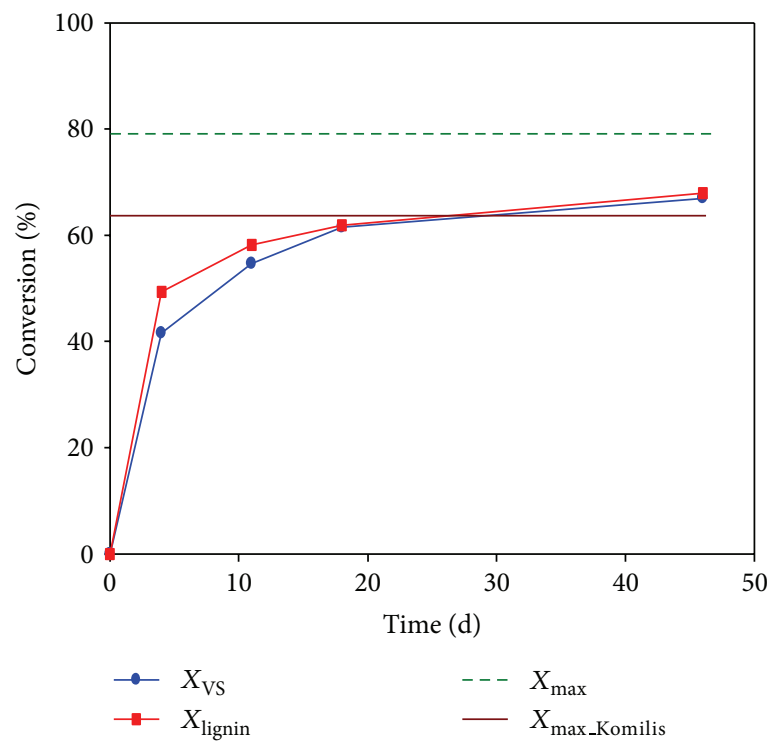

(b)

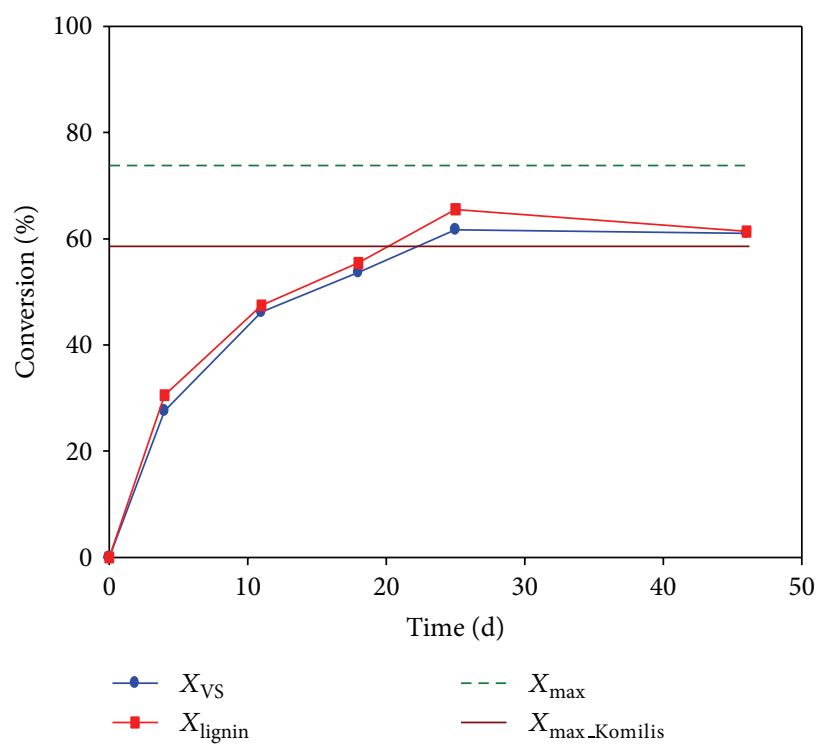

(c)

FIGURE 3: Conversion of organic matter obtained experimentally, $X_{\mathrm{VS}}$, and by quantification of lignin content, $X_{\text {lignin }}$, in reactors (a) SD1, (b) SD2 and (c) SD3.

of EC were measured in the extracts of samples from 11 to 18 days $(10-12 \mathrm{mS} / \mathrm{cm})$, which may also have contributed to these low germination levels. After 39 days of composting, GI remained below $30 \%$, indicating that the materials were still very phytotoxic.

When rice husk was used as bulking agent, Figure 4(b), initial mixtures presented higher GI values in comparison with SD mixtures, probably due to the lower phytotoxicity presented by RH. During composting, after an increase in GI levels over time until day 4, all processes tend to decrease this parameter where it can be seen that germination index evolution for RH1 and RH3 followed similar trends for days $0,4,11$, and $39(P>0.05)$. Once again, this decrease can be attributed to the formation of phytotoxic substances during the most active phase of composting. In the case of RH1 and RH3, final GI values of $67.1 \%$ and $72.2 \%$ were observed, respectively, that are also statistically equal $(P=0,403)$ and thus both moderately phytotoxic and immature (GI $<80 \%)$ [5]. It is important to note that, on the contrary to some results from the literature $[29,30]$, the phytotoxicity profiles over time based on GI do not always present a smooth monotone increasing behavior that stabilizes in a plateau.

In Figure 5, the GI observed at the end of the first eighteen days was represented as a function of the cumulative OUR observed for the two sets of experiments with sawdust and rice husk. 


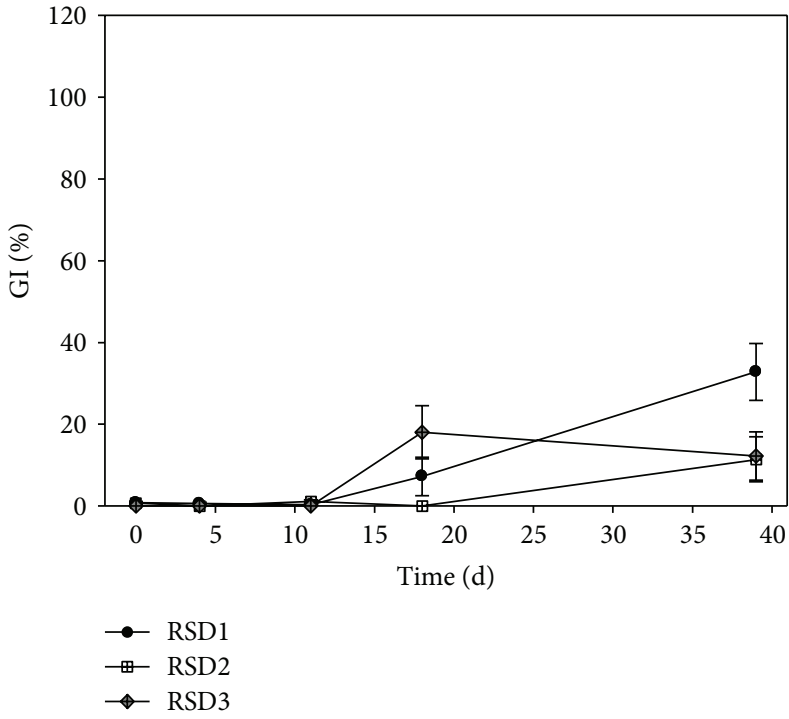

(a)

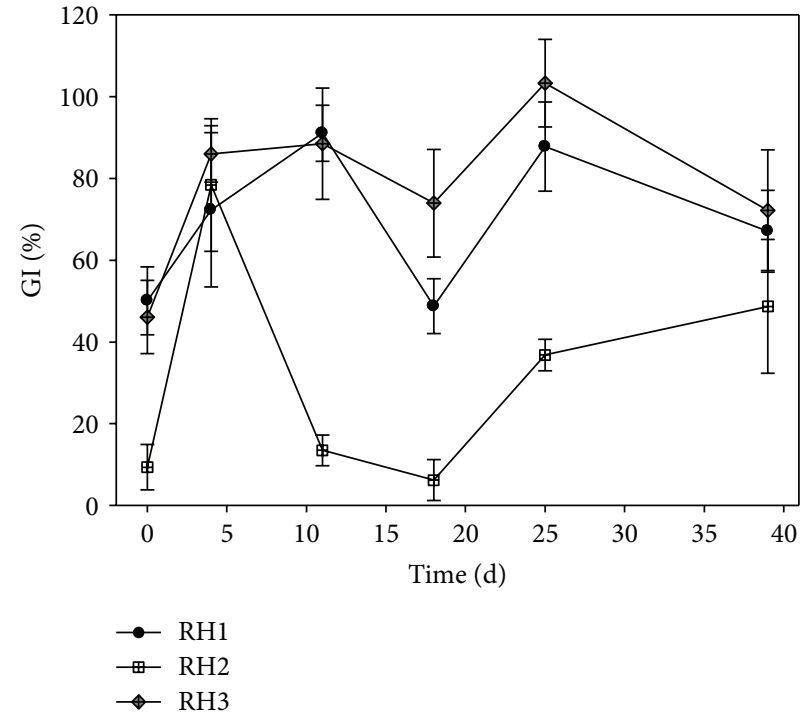

(b)

FIGURE 4: GI profiles during composting processes (a) SD1 to SD3 and (b) RH1 to RH3.

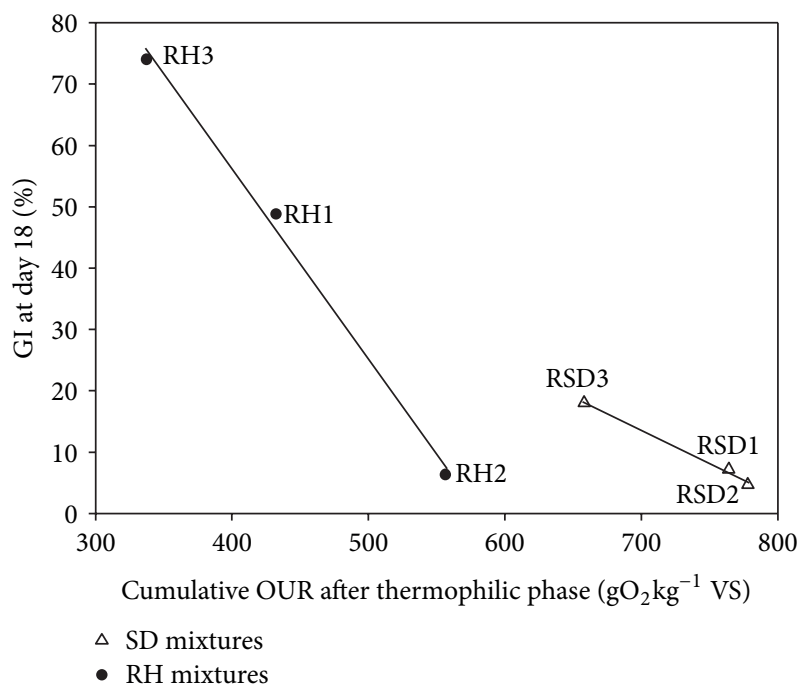

FIGURE 5: Relationship of germination index at day 18 of composting and cumulative OUR after thermophilic phase.

From these results it was possible to find that for each bulking agent used, there is a proportional relationship between the cumulative OUR attained after the thermophilic phase $\left(T<40^{\circ} \mathrm{C}\right)$ and the germination index at day 18 of composting. Thus, higher cumulative OUR, which is related to microbial activity and breakdown of organic substances, seems to induce lower germination levels.

In summary, as the biological activity progresses during composting, the phytotoxicity of the ingredients tested was more successful for mixtures where rice husk was used as bulking agent, although the composts obtained after 39 days were still immature. This means that more composting time is necessary to obtain final products with low levels of phytotoxicity.

\section{Conclusions}

This study mainly analysed changes in phytotoxicity during composting of two sets of experiments involving sawdust and rice husk as bulking agents. Different biowastes were combined in order to obtain balanced mixtures. The analysis of the phytotoxicity of individual ingredients through the germination index revealed that all of them impair germination of Lepidium sativum, and the sawdust was even classified as very phytotoxic.

All mixtures revealed regular progress in terms of temperature profiles over time inside the reactors, where the three characteristics phases were well observed. The oxygen uptake rate (OUR) profiles were monitored as well, and the mixtures tested were categorized as moderate to high biodegradable. The biodegradability was followed over time for the set of experiments involving sawdust. The results obtained from the quantification of lignin were in good agreement with the observed conversion of organic matter. Some empirical correlations proposed in the literature adequately predict the maximum biodegradability for specific mixtures.

The germination index profiles along time may be significantly different between experiments with sawdust or with rice husk as bulking agents. Sawdust seems to impair seed germination to a greater extent, and after 39 days of composting, GI remained below $30 \%$. In the case of rice husk, it was possible to reach $70 \%$ of GI at the end of the same period. Our results revealed that, at a certain point, there is a proportional relationship between the cumulative oxygen uptake rate and the germination index. Indeed, higher cumulative OUR provoked lower germination index. 
The phytotoxicity test using seeds of Lepidium sativum is a reliable mean of measuring the toxicity associated with the different contaminants that may be present in a water extract, once it is fast and low-priced.

\section{Acknowledgment}

CERNAS is supported by National Funds through Foundation for Science and Technology (FCT ) under the project PEst-OE/AGR/UI0681/2011.

\section{References}

[1] R. T. Haug, The Practical Handbook of Compost Engineering, CRC-Press, Boca Raton, Fla, USA, 1993.

[2] S. Gajalakshmi and S. A. Abbasi, "Solid waste management by composting: state of the art," Critical Reviews in Environmental Science and Technology, vol. 38, no. 5, pp. 311-400, 2008.

[3] N. Trautmann and M. Krasny, Composting in the Classroom, Cornell University Press, 1997.

[4] M. of A. \& Food, Resource Management Branch, Ministry of Agriculture, Food and Fisheries, Abbotsford, Canada, 1996.

[5] M. Tosin, F. Degli-Innocenti, and C. Bastioli, "Effect of the composting substrate on biodegradation of solid materials under controlled composting conditions," Journal of Enviornmental Polymer Degradation, vol. 4, no. 1, pp. 55-63, 1996.

[6] A. de Guardia, C. Petiot, and D. Rogeau, "Influence of aeration rate and biodegradability fractionation on composting kinetics," Waste Management, vol. 28, no. 1, pp. 73-84, 2008.

[7] A. de Guardia, P. Mallard, C. Teglia et al., "Comparison of five organic wastes regarding their behaviour during compostingpart 2: nitrogen dynamic," Waste Management, vol. 30, no. 3, pp. 415-425, 2010.

[8] S. Ponsá, T. Gea, and A. Sánchez, "Different indices to express biodegradability in organic solid wastes," Journal of Environmental Quality, vol. 39, no. 2, pp. 706-712, 2010.

[9] R. Barrena, T. Gea, S. Ponsá et al., "Categorizing raw organic material biodegradability via respiration activity measurement: a review," Compost Science \& Utilization, vol. 19, no. 2, pp. 105113, 2011.

[10] L. Berthe, C. Druilhe, C. Massiani, A. Tremier, and A. de Guardia, "Coupling a respirometer and a pycnometer, to study the biodegradability of solid organic wastes during composting," Biosystems Engineering, vol. 97, no. 1, pp. 75-88, 2007.

[11] M. López, O. Huerta-Pujol, F. X. Martínez, and M. Soliva, "Approaching compost stability from Klason lignin modified method: chemical stability degree for $\mathrm{OM}$ and $\mathrm{N}$ quality assessment," Resources, Conservation and Recycling, vol. 55, no. 2, pp. 171-181, 2010.

[12] R. Barrena, J. Turet, A. Busquets, M. Farrés, X. Font, and A. Sánchez, "Respirometric screening of several types of manure and mixtures intended for composting," Bioresource Technology, vol. 102, no. 2, pp. 1367-1377, 2011.

[13] M. Tuomela, M. Vikman, A. Hatakka, and M. Itävaara, "Biodegradation of lignin in a compost environment: a review," Bioresource Technology, vol. 72, no. 2, pp. 169-183, 2000.

[14] D. P. Komilis and R. K. Ham, "The effect of lignin and sugars to the aerobic decomposition of solid wastes," Waste Management, vol. 23, no. 5, pp. 419-423, 2003.
[15] S. M. Tiquia, "Reduction of compost phytotoxicity during the process of decomposition," Chemosphere, vol. 79, no. 5, pp. 506512, 2010.

[16] M. Gao, F. Liang, A. Yu, B. Li, and L. Yang, "Evaluation of stability and maturity during forced-aeration composting of chicken manure and sawdust at different $\mathrm{C} / \mathrm{N}$ ratios," Chemosphere, vol. 78, no. 5, pp. 614-619, 2010.

[17] D. Cabañas-Vargas, M. Sánchez-Monedero, S. Urpilainen, A. Kamilaki, and E. Stentiford, "Assessing the stability and maturity of compost at large-scale plants," Ingeniería, vol. 9, pp. 2530, 2005.

[18] P. Helfrich, B. Chefetz, Y. Hadar, Y. Chen, and H. Schnabl, "A novel method for determining phytotoxicity in composts," Compost Science and Utilization, vol. 6, no. 3, pp. 6-13, 1998.

[19] T. Nolan, S. M. Troy, M. G. Healy, W. Kwapinski, J. J. Leahy, and P. G. Lawlor, "Characterization of compost produced from separated pig manure and a variety of bulking agents at low initial C/N ratios," Bioresource Technology, vol. 102, no. 14, pp. 7131-7138, 2011.

[20] G. H. Yu, M. J. Wu, Y. H. Luo, X. M. Yang, W. Ran, and Q. R. Shen, "Fluorescence excitation-emission spectroscopy with regional integration analysis for assessment of compost maturity," Waste Management, vol. 31, no. 8, pp. 1729-1736, 2011.

[21] D. P. Komilis and I. S. Tziouvaras, "A statistical analysis to assess the maturity and stability of six composts," Waste Management, vol. 29, no. 5, pp. 1504-1513, 2009.

[22] T. Gea, R. Barrena, A. Artola, and A. Sánchez, "Monitoring the biological activity of the composting process: oxygen uptake rate (OUR), respirometric index (RI), and respiratory quotient (RQ)," Biotechnology and Bioengineering, vol. 88, no. 4, pp. 520527, 2004.

[23] S. M. Tiquia, N. F. Y. Tam, and I. J. Hodgkiss, "Effects of composting on phytotoxicity of spent pig-manure sawdust litter," Environmental Pollution, vol. 93, no. 3, pp. 249-256, 1996.

[24] N. Zhu, "Composting of high moisture content swine manure with corncob in a pilot-scale aerated static bin system," Bioresource Technology, vol. 97, no. 15, pp. 1870-1875, 2006.

[25] C. J. An, G. H. Huang, Y. Yao, W. Sun, and K. An, "Performance of in-vessel composting of food waste in the presence of coal ash and uric acid," Journal of Hazardous Materials, vol. 203-204, pp. 38-45, 2012.

[26] B. Scaglia, F. Tambone, P. L. Genevini, and F. Adani, "Respiration index determination: dynamic and static approaches," Compost Science and Utilization, vol. 8, no. 2, pp. 90-98, 2000.

[27] M. Delgado, "Phytotoxicity of uncomposted and composted poultry manure," African Journal of Plant Science, vol. 4, pp. 154$162,2010$.

[28] M. Gómez-Brandón, C. Lazcano, and J. Domínguez, "The evaluation of stability and maturity during the composting of cattle manure," Chemosphere, vol. 70, no. 3, pp. 436-444, 2008.

[29] M. Gao, B. Li, A. Yu, F. Liang, L. Yang, and Y. Sun, "The effect of aeration rate on forced-aeration composting of chicken manure and sawdust," Bioresource Technology, vol. 101, no. 6, pp. 18991903, 2010.

[30] Y. Xiao, G. M. Zeng, Z. H. Yang et al., "Continuous thermophilic composting (CTC) for rapid biodegradation and maturation of organic municipal solid waste," Bioresource Technology, vol. 100, no. 20, pp. 4807-4813, 2009. 

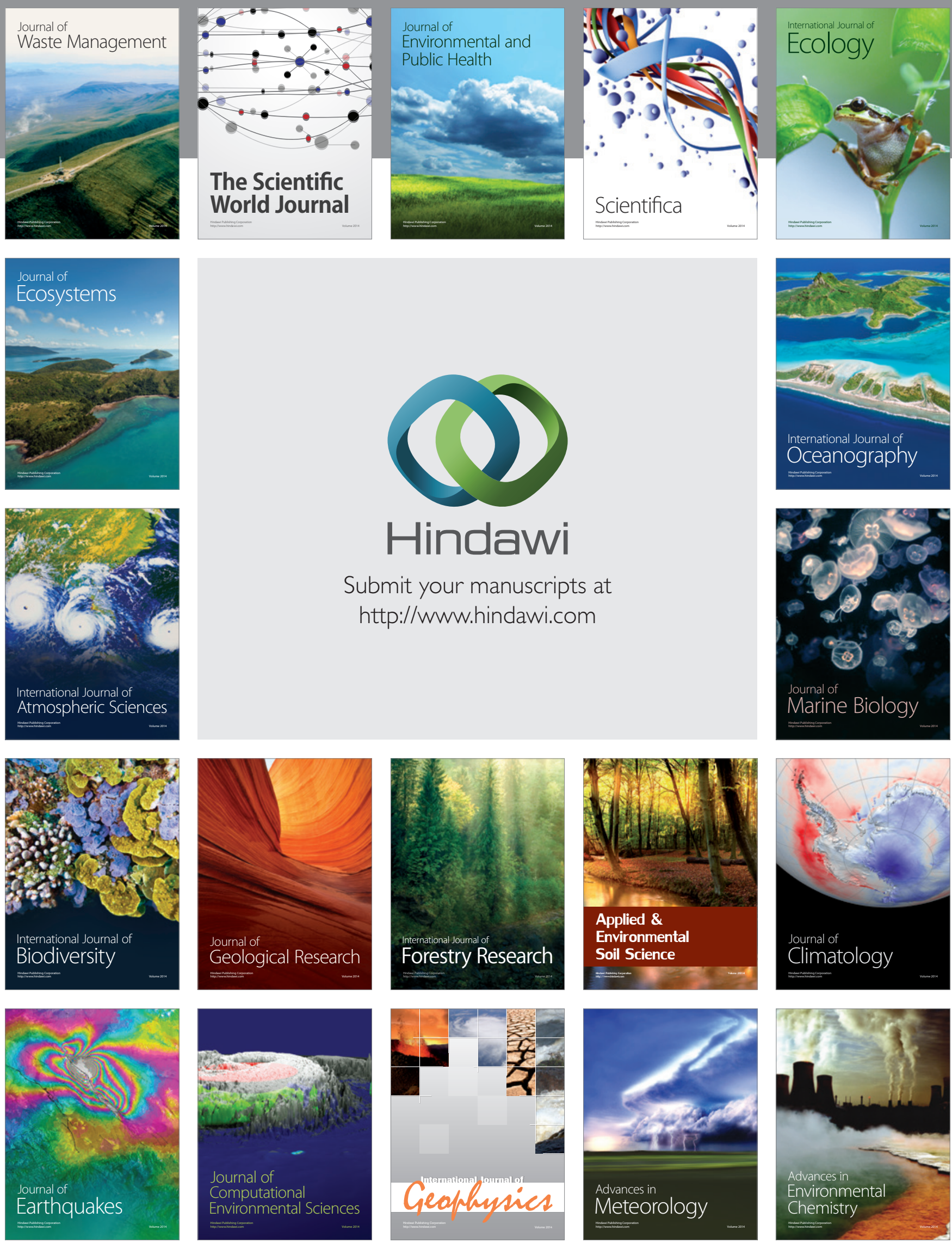